\title{
DEFORESTATION AND ITS IMPACTS ON CLIMATE CHANGE AN OVERVIEW OF PAKISTAN
}

\author{
ARSHAD ALI, SOMANA RIAZ, SHAHID IQBAL \\ National University of Sciences and Technology \\ Islamabad, Pakistan \\ aliarshad08@yahoo.com
}

\begin{abstract}
Forests are one the main natural factors that regulate and determine climate, weather patterns and amount of $\mathrm{CO}_{2}$ of an area. With rapid industrialization and rapid urbanization there is a significant increase in deforestation and as a consequence rise in global mean surface temperatures. Rapid and unchecked cut down of forest cover has resulted in some of the worst disasters during the last decades. This paper focuses on studying the role of deforestation, its influence on climate change phenomena and its consequences in Pakistan.
\end{abstract}

KEY WORDS: climate change, deforestation, catastrophic events in Pakistan.

\section{INTRODUCTION}

Climate change is one of the greatest concerns to mankind in recent times. Climate pattern of an area shapes the life style, livelihood and culture of an area. Majority of the world population experience the impacts of climate change on their socioecological practices through variation in annual precipitation, temperature and sea-level over long-time span, or through the increasing intensity and frequency of hydrometeorological hazards (floods, storms, fires, cyclones, heatwaves, and droughts) and epidemics (Derbyshire, Owen 1997). Apart from these climate related events there 
are other high impact phenomena of glacial melting and permafrost which may rise the global sea-levels by several meters, disintegration of the thermohaline circulation that in turn may cause considerable climate changes in the northern hemisphere, and regional shift in the Asian Monsoon system and the El Niňo Southern Oscillation phenomenon.

The impacts of climate change are devastating in developing countries due to lack of capacity in accordance with the changing climate. Rich countries effectively violate the human rights of thousands of the world's poorest people by excessive exploitation of natural resources. Continuous emission of greenhouse-gases from industrialized nations is resulting in hydro-meteorological events, sea-level rise, and seasonal unpredictability (Yuksel 2014, Adnan et al. 2011). The consequences of uncertain seasonal variation are scarcity of water and food scarcity (failed harvests), rising sea level, destroyed homes, and increasing health crises, which are affecting millions of peoples (Malone et al. 2009).

Strategies designed for mitigating climate change are focused on reducing the emissions of greenhouse gases (GHGs), particularly carbon dioxide $\left(\mathrm{CO}_{2}\right)$. One of the main causes of $\mathrm{CO}_{2}$ emissions is deforestation. Forests act as natural filters for carbon dioxide absorption in the atmosphere. They store more carbon than they release and are termed as $\mathrm{CO}_{2}$ sinks in their natural state (Negar and Jean 2014). Approximately more than a quarter of the earth's land surface is covered forests which store more than three quarters of carbon in terrestrial setting (Percy et al. 2003).

\section{CLIMATE CHANGE AND ITS IMPACTS}

The Intergovernmental Panel on Climate Change (IPCC), has forecasted an increase in the average temperature of the world within the range $1 \cdot 4-5 \cdot 8^{\circ} \mathrm{C}$ by 2100 . Research carried out by four independent institutions analyzed that the decade (2000-2009) was the warmest on record. Since 1750 there has been an observed increase of $31 \%$ in the level of atmospheric carbon dioxide $\left(\mathrm{CO}_{2}\right)$. Fossil fuel consumption and deforestation at the present rate has resulted in an unprecedented increase of $\mathrm{CO}_{2}$ in the atmosphere for the past 20000 years (Climate Change 2001) - Figure 1. Over the 20th century there has been an increase of about $0.6^{\circ} \mathrm{C}$ in the average surface temperature of the earth and the process had continued since 1861 (Afreen et al. 2012, Derbyshire et al. 1984). Since the late 1950s there has been an increase in global temperature in the increases in the lowest 8 kilometers of the atmosphere and in surface temperature have been similar at $0.1^{\circ} \mathrm{C}$ per decade (Figs 2a,b). Satellite data observation indicates a decrease of about $10 \%$ in the snow cover has occurred since the late 1960s, with a widespread retreat of mountain glaciers in non-polar regions. There has been an increase of about 0.1-0.2 meters increase in the global sea level as a consequence of climate change (Aaron and Matthew 2014). 
The Ten Hottest Years on Record

highest rank $=$ warmest year since recording began in 1880

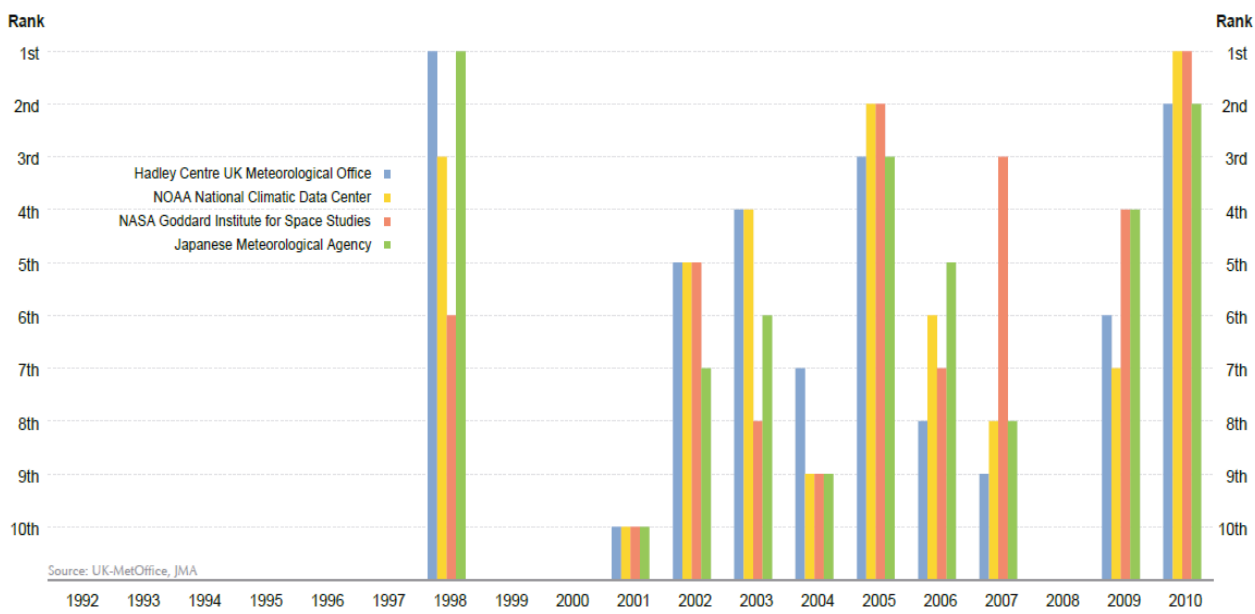

Figure 1. The ten hottest years

The ten hottest years on record have all occurred since 1998. Eighteen out of the last 21 years feature among the 20 warmest years on record since (reliable) recording of temperature started in 1880 . These data indicates short-term spatial and temporal variability but there is a clear long-term trend is one of global warming (James and Dougall 1989).

Variations of the Earth's surface temperature for:

(a) the past 140 years

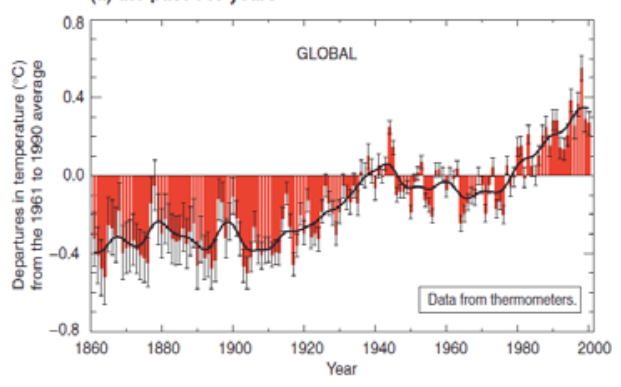

(b) the past 1,000 years

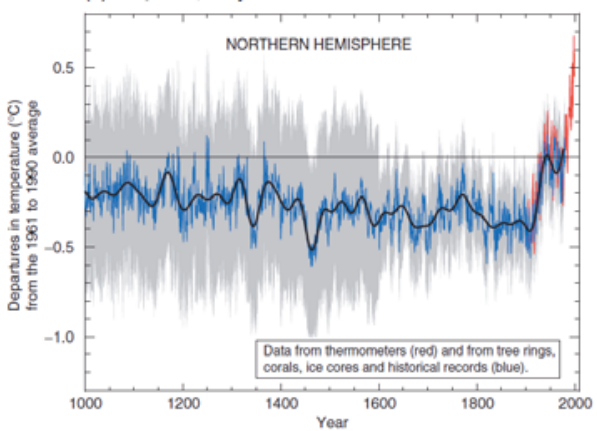

Figure 2ab. Earth's surface temperature variation over the last 140 years and the last millennium (Edward et al. 2013)

Various sectors together contribute over $60 \%$ of all greenhouse gas (GHG) emissions that include the energy supply sector, forestry and industry/manufacturing sectors (Fig. 3). Worldwide deforestation mainly contribute to forestry as trees cut down for land uses (agriculture or construction) the soil loses its capacity to absorb carbon dioxide, and if left to rot or burned, emit stored $\mathrm{CO}_{2}$ in it. 
Over $60 \%$ of Greenhouse Gases are

emitted by three economic sectors

Which sectors emit the most Greenhouse Gases?

Per Cent contribution to global anthropogenic GHG emissions, 2004

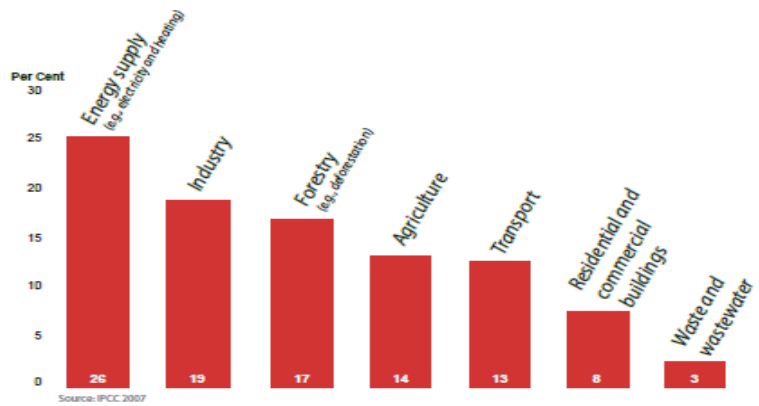

Figure 3. Greenhouse gases (GHG) emissions by the sectors (acc. Harald, 2014)

Energy supply, industry/manufacturing and forestry sectors collectively account for over $60 \%$ of all greenhouse gas (GHG) emissions. The forestry's contribution is basically through deforestation worldwide, as trees cut down to clear space for agriculture and other land uses can no longer absorb carbon dioxide, and if left to rot or burned, emit $\mathrm{CO}_{2}$ stored in trunks and leaves.

During the $20^{\text {th }}$ century, more than 10 million people lost their lives as a result of natural catastrophes, with almost of them becoming victims of floods. Floods have been affecting communities ever since the history of mankind, followed by earthquakes, claiming 169000 lives. Between 1985 and 1999, all the natural hazards that occurred included $37 \%$ windstorms, $28 \%$ floods, and $15 \%$ earthquakes. The remaining $20 \%$ included fires and landslides. Asia, the most populous continent, has been particularly hard hit. Statistical records reveal that between 1985 and 1999, Asia suffered about $77 \%$ of all casualties, $90 \%$ of all displaced (homelessness), and $45 \%$ of all recorded (James and Wescoat 1991). With the onset of climate change and increasing intensity of natural hazards there is a greater need to adopt mitigation methods in accordance with the changing climate.

\section{DEFORESTATION - CONTRIBUTING FACTOR OF CLIMATE CHANGE}

Deforestation is the loss/removal of tree cover, as a result of forests being cleared for other land uses such as farming or ranching. Some limit the definition of deforestation to the permanent conversion of forests to another habitat. Deforestation activities 
affect carbon flux in the soil, vegetation, and atmosphere. Deforestation results in soil degradation, carbon emission as a result of plant decomposition left on forest floor, albedo effect, and intensification of hydro-meteorological hazards.

Approximately $30 \%$ of the Earth's land mass is covered by forests (Percy et al. 2003). Forests influence the global climatic pattern through climate through physical, chemical, and biological processes that regulates the hydrological cycle, temperature stability and atmospheric composition. There has been a significant decrease in primary forest area by 300 million ha since 1990. Between 2000 and 2010, around 13 million hectares of forest were converted to other uses or naturally lost, compared to 16 million hectares per year during the earlier decade (Joseph et al. 2004). This results not only in degradation of biodiversity, but also adds $12-15 \%$ to global warming by releasing $\mathrm{CO}_{2}$ into the atmosphere and impeding further $\mathrm{CO}_{2}$ storage (Fig. 4). Forests cover $\sim 42$ million $\mathrm{km}^{2}$ in tropical, temperate, and boreal lands. Forests provide social, economic, ecological and aesthetic benefits to natural systems and people. They act as a hub for biodiversity, act as food supply, have medicinal and economic value, help in hydrological cycle regulation, protect soil cover, and serve as aesthetic and recreational sites. Additionally, forests influence climate through exchanges of water, carbon dioxide, energy and other chemical species with the atmosphere (Joseph et al. 2004, Song et al. 2014).

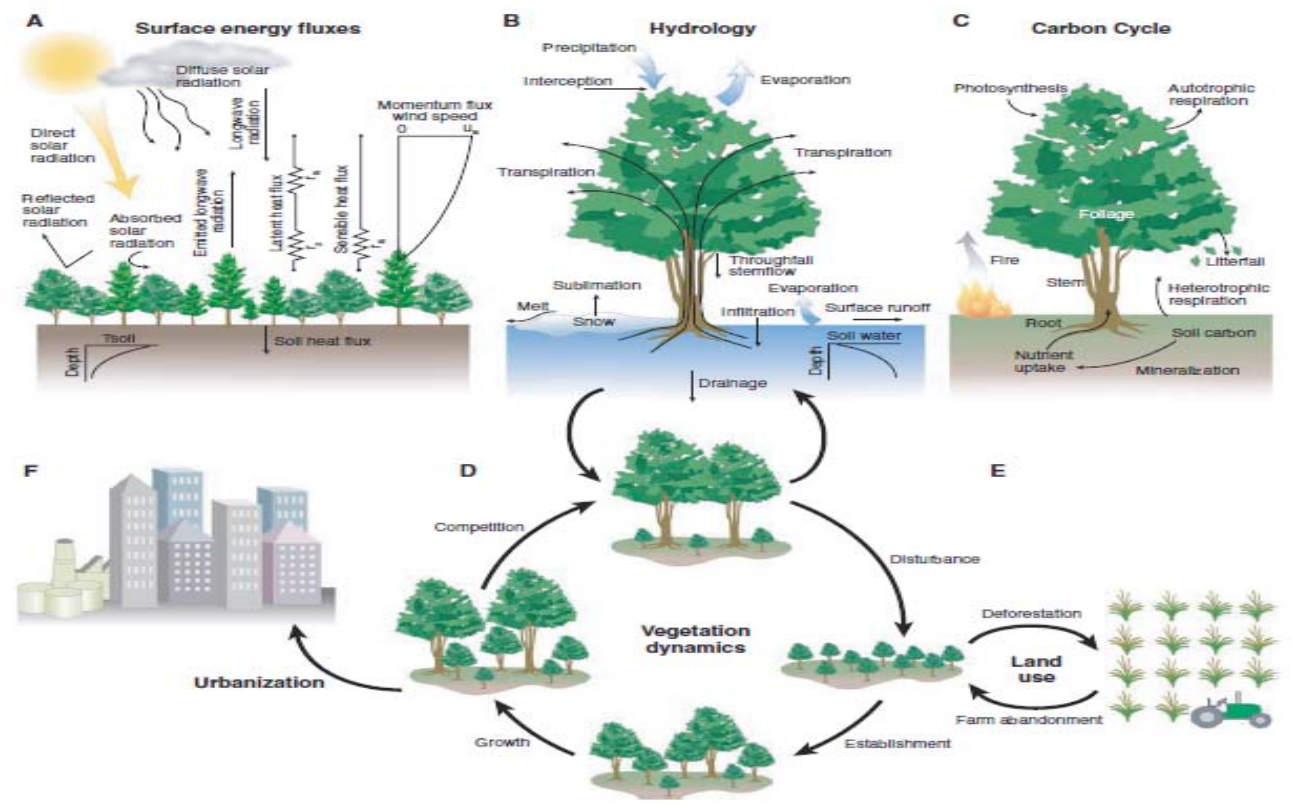

Figure 4. Biogeophysics, Biogeochemistry, and biogeography of terrestrial ecosystems (Land surface parameterization)

(A) Surface energy fluxes and (B) The hydrologic cycle, (C) Carbon cycle and (D) Vegetation dynamics so that plant ecosystems respond to climate change, (E) Land use, (F) Urbanisation (Heike and Lisa 2013) 
Forests store $\sim 45 \%$ of terrestrial carbon and can sequester large amounts of carbon (Percy et al. 2003). Forests have low surface albedo and can mask the high albedo of snow, and help in regulating surface temperatures of the earth. Forests play a key role in regulating the hydrologic cycle through evapotranspiration and can be used as an effective tool to mitigate climate change Climate model simulations show that tropical forests maintain high rates of evapotranspiration, increase precipitation and results in a decrease in surface air temperature. Deforestation on the other hand increases surface temperature, excessive emission rates of carbon dioxide, soil degradation and increase in surface runoff resulting in flash floods. Removal of forest cover alters global and regional climate patterns and results in catastrophic rainfall spells followed by prolonged dry periods (Strasser et al. 2014). During the last few decades increase in urbanization and change in land use have resulted in massive increase in the rate of deforestation causing a distortion of global climate patterns and increase in catastrophic hydro-meteorological events (Fig. 5).
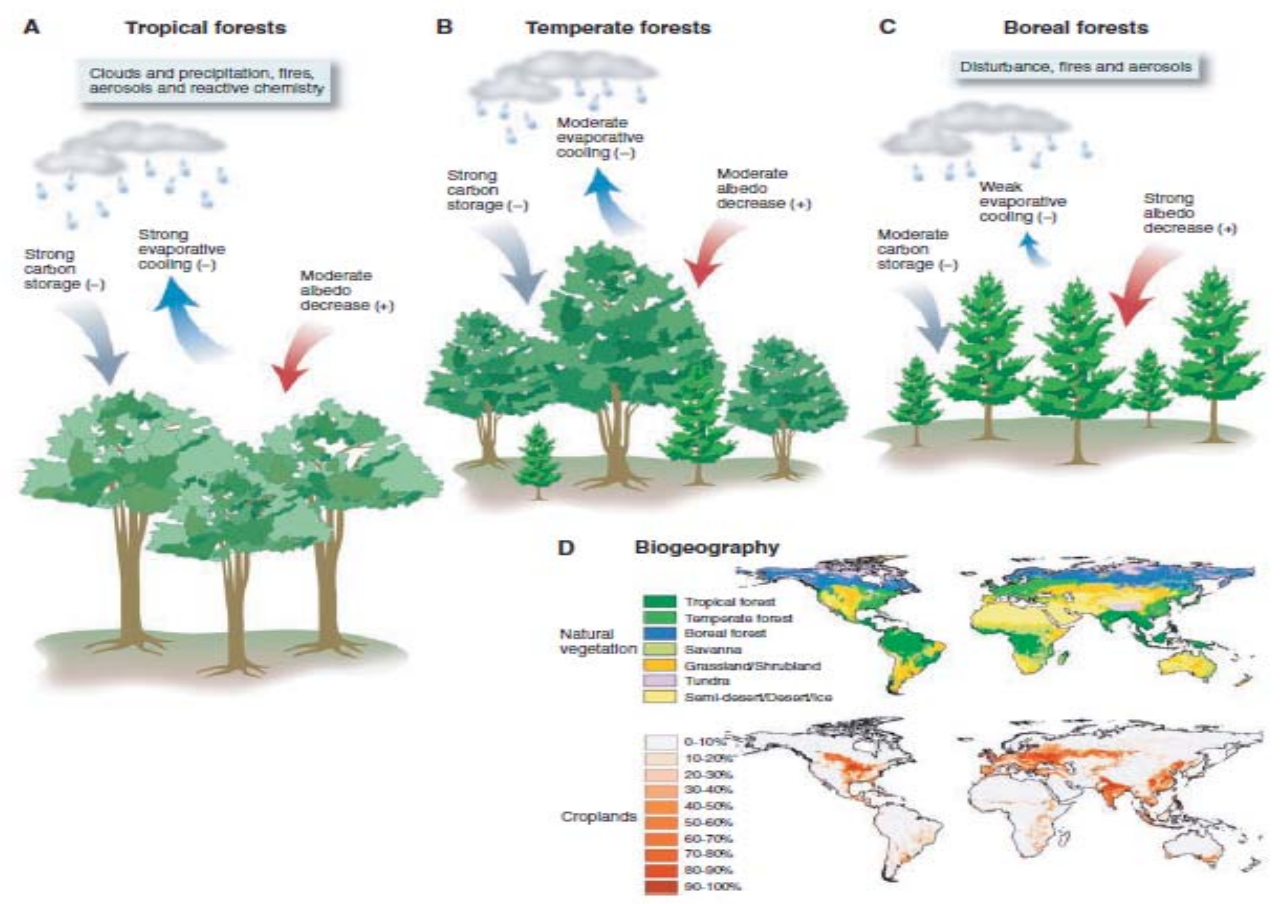

Figure 5. Climate services in different forest zones

(A) tropical, (B) temperate, and (C) boreal forests, (D) Natural vegetation biogeography in the absence of human uses of land and cropland (percent cover) during the 1990s

(Khawaja et al. 2007) 


\section{DEFORESTATION AND CLIMATE CHANGE IN THE SOUTH ASIA}

The Hindu Kush-Himalaya mountain system is the largest ice cover outside the polar region including more than $100000 \mathrm{~km}$ glacial cover and is termed as the Third Pole. It is one of the most complex and diverse mountain systems in the world. About 10 of Asia's largest rivers originate here. This mountain system stretches for $3500 \mathrm{~km}$ covering some of the world's driest and environments. It rises for about $8 \mathrm{~km}$ vertically through almost every life zone existing on Earth, and lies at the geographical centre of most dense concentration of humans. It is recognized as an extremely delicate environment that is particularly vulnerable to global warming (Kenneth 1998). The region is highly vulnerable to frequent natural hazards and poses a constant threat to the communities living in the Himalayan region and downstream communities. Climate change is expected to intensify in frequency and magnitude of extreme weather events leading to disasters.

Climate change impacts in the Hindu Kush-Himalaya region and downstream areas, including the Indo-Gangetic plains are particularly threatened by climate change. A large section of the population depends on climate sensitive livelihoods which increase their vulnerability to climate change. Poverty and lack of coping capacity increases the risk of adverse impacts of climate change in the Himalayas. The mountain dwellers heavily depend of forests to meet their fuel requirement. This has resulted in deforestation over large area at a rapid rate and further increasing the risk of flooding, landslides, rapid rate of glacier melting, depletion of fresh water sources and droughts in the region.

One of the most frequent and disastrous natural hazards that affect the South Asian countries, particularly the Himalayan region is floods (Fig. 6). During the past two decades the region has suffered some of the worst flood disasters of human history. Deforestation has adversely affected the climate pattern and stability in South Asia in the recent years. Asia comprises of about $15 \%$ of the global forest area. The impacts of deforestation are far more adverse than in any other part of the world. It is because of the influence of forest cover on the regional hydrological cycle, Asian monsoon pattern, and circulation pattern that effect not only the region but has global impact. Some of these adverse impacts would result in variation in the following (Schweikert et al. 2014):

- Rainfall: There would be an expected decrease in the annual precipitation rate in the region as a result of deforestation. There would be prolonged dry spells followed but short periods of intense rains.

- Temperature: Forest cover regulates the air and surface temperature by absorbing carbon dioxide, with a decrease in the forest cover there would a significant increase in the temperature of the region. An increase of about $1{ }^{\circ} \mathrm{C}$ is predicted for the region due to deforestation and reduced rate of evaporative cooling.

- The study on the effects of deforestation on the summer monsoon system in Asia and concluded that deforestation results in weakening of the monsoon system in the 
upland areas due to high wind speeds and low water vapor content but increased intensity and intense rainfalls in areas downwind of deforestation.

- Mangrove deforestation: Mangrove forests provide a barrier against tides and waves. With the increasing trend of deforestation along the coastal belts of the region creates an imbalance in the natural water chemistry and expose the coastal community to the direct impacts of tides and waves.

- Teleconnections: These include the effects associated with deforestation or the secondary effects of deforestation. Rapid decrease of forest cover in the area will not only alter the Asian climate pattern but will influence the global meteorological circulation patterns as well leading to intense climatic disasters.

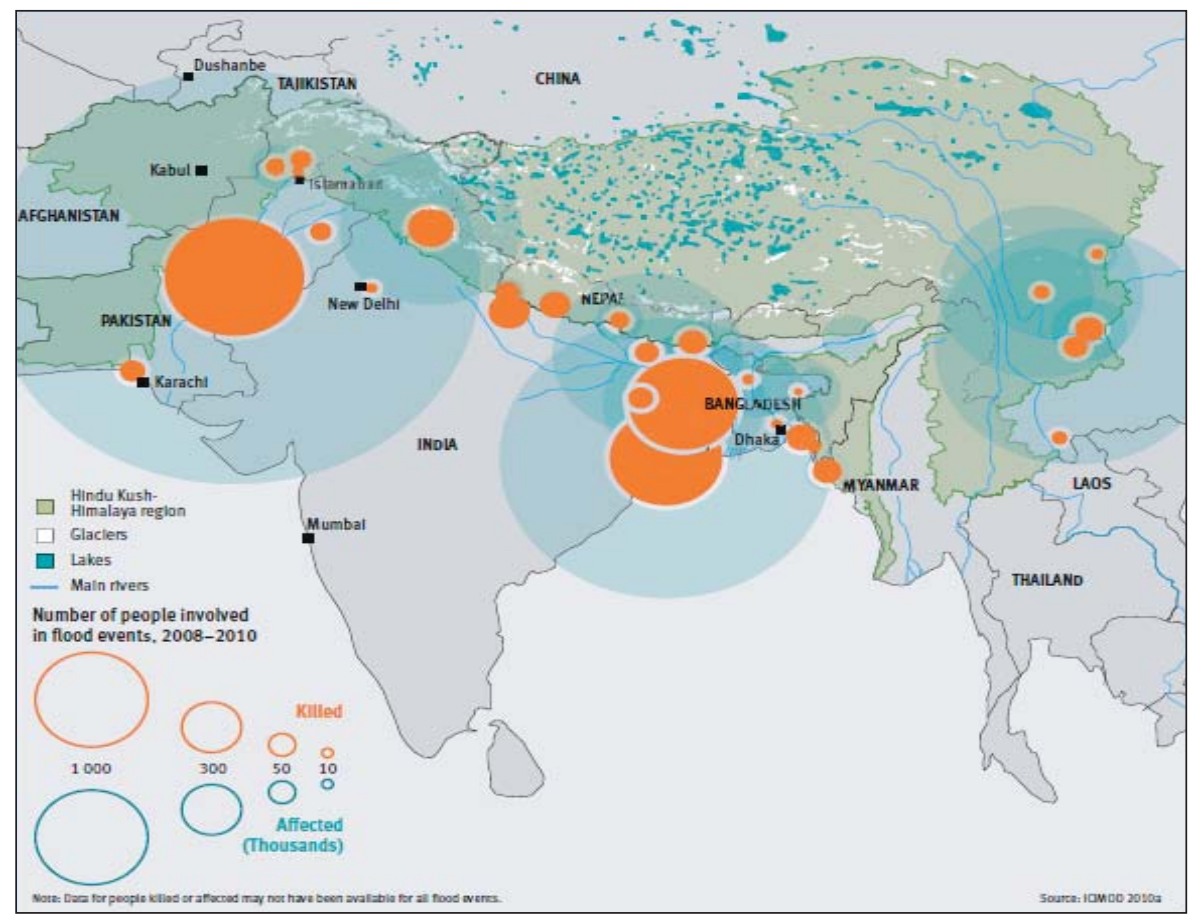

Figure 6. Map showing some of the devastating floods in the Himalayan countries with an estimated number of people affected in each country

\section{DEFORESTATION AND CLIMATE CHANGE IN PAKISTAN}

Pakistan has most of its forests located in its northern parts in the highlands of Khyber Pakhtunkhwa, Gilgit-Baltistan and Azad Kashmir. About 39 thousand hectares of forests are vanishing annually at an annual depletion rate of more than $1.5 \%$ (Schweikert et al. 2014). The increasing trend of deforestation has negative impacts on the production and protection of the forests and livelihoods of those living around 
the forests. Due to illegal exploitation and poor implementation of legislation the forest cover is depleting at a devastation rate in the country. As a consequence of deforestation there is increasing risk of landslides, slope destabilization, floods, increase surface runoff and soil erosion. After the Kashmir earthquake (2005) an increased risk of landslides and debris flow was encountered due to exploitation of forests.

In 2010 Pakistan experienced the worst flood of its history. Scientists termed the unprecedented rate of monsoon rains as impacts of climate change in the region. During the catastrophic event deforestation again aggravated the situation. Natural and anthropogenic conditions played a combined role in creating a disastrous situation. Soil degradation and deforestation resulted in increased surface runoff and soil erosion.

\section{CONCLUSION}

Forests provide a protection to the biodiversity protects the soil cover and regulates hydrological cycle, atmospheric temperatures and help in militating against the impacts of climate change. With the increasing population and urbanization trend there is an increase in the rate of deforestation with has resulted in the disruption of natural atmospheric and climatic patterns and enhanced the devastating impacts of natural hazards.

\section{RECOMMENDATIONS}

- Forests management can be used an effective tool to cope with the increasing impacts of climate change, particularly in the mountainous terrain.

- Land use and forest protection regulations should be implemented with sincerity and with the consent of the community.

- Community awareness and training must be organized for effective afforestation and forest conservation.

\section{REFERENCES}

Aaron D. and Matthew A.P., 2014, Heart rate change and attitudes to global warming: A conceptual replication of the visceral fit mechanism, Journal of Environmental Psychology, 38, 10-16.

Adnan A.T., Pierre C., Yves A., Luc N. and Bashir A., 2011, Modeling snowmelt-runoff under climate scenarios in the Hunza River basin, Karakoram Range, Northern Pakistan, Journal of Hydrology, 409, 1-2, 104-117.

Afreen S., James L., Wescoat J., Salal H. and Khurram A., 2012, An empirical analysis of the hydropower portfolio in Pakistan, Energy Policy, 50, 228-241. 
Derbyshire E. and Owen L., 1997, Quaternary glacial history of the Karakoram Mountains and Northwest Himalayas: A review, Quaternary International, 38/39, 85-102.

Derbyshire E., Li J., Perrott F.A., Shuying X. and Waters R.S., 1984, Quaternary glacial history of the Hunza Valley, Karakoram Mountains, Pakistan, K.J. Miller (ed.), The International Karakoram Project, 456-495.

Edward R.C., Jonathan G.P., Moinuddin A., Connie A., Woodhouse P.F., Muhammad U.Z., Muhammad W. and Nasrullah K., 2013, Five centuries of Upper Indus River flow from tree rings, Journal of Hydrology, 486, 365-375.

Harald W., 2014, Emerging lessons on designing and implementing mitigation actions in five developing countries, Climate and Development, 6, 1-3.

Heike H. and Lisa A., 2013, Flooding in the Indus River basin - A spatiotemporal analysis of precipitation records, Global and Planetary Change, 107, 25-35.

James L. and Wescoat J., 1991, Managing the Indus River basin in light of climate change: Four conceptual approaches, Global Environmental Change, 1, 5, 381-395.

James W. and Dougall M., 1989, Tectonically-induced diversion of the Indus River west of the Salt Range, Pakistan, Palaeogeography, Palaeoclimatology, Palaeoecology, 71, 3-4, 301-307.

Joseph S., Rita P., Wright M., Rafique, M. and Afzal K., 2004, Landscapes, soils, and mound histories of the Upper Indus Valley, Pakistan: new insights on the Holocene environments near ancient Harappa, Journal of Archaeological Science, 31, 6, 777-797.

Kenneth H., 1998, Catastrophic landslides and their effects on the Upper Indus streams, Karakoram Himalaya, northern Pakistan, Geomorphology, 26, 1-3, 47-80.

Khawaja F., Dirk H. and Boer D., 2007, Spatial patterns and variation of suspended sediment yield in the upper Indus River basin, northern Pakistan, Journal of Hydrology, 334, 3-4, 368-387.

Malone R.W., Meek D.W., Hatfield J.L., Mann M.E., Jaquis R.J. and Ma L., 2009, Quasi-biennial corn yield cycles in lowa, Agricultural and Forest Meteorology, 149, 6-7, 1087-1094.

Negar H. and Jean P. B., 2014, Geomorphological analysis of the drainage system on the growing Makran accretionary wedge, Geomorphology, 209, 111-132.

Percy K.E. , Jandl R., Hall J.P. and Lavigne M., 2003, The Role of Forests in Carbon Cycles, Sequestration, and Storage, International Union of Forest Research Organizations, 1.

Schweikert A., Paul C., Kyle K. and Xavier E., 2014, The infrastructure planning support system: Analyzing the impact of climate change on road infrastructure and development, Transport Policy, 35, 146-153.

Song F., Qi H., Wei H., Chang H.H., Ruopu L. and Zhenghong T., 2014, Tang. Projected climate regime shift under future global warming from multi-model, multi-scenario CMIP5 simulations, Global and Planetary Change, 112, 41-52.

Strasser U., Vilsmaier F., Prettenhaler T., Marke R., Steiger A., Damm F., Hanzer R., Wilcke J. and Stötter J., 2014, Coupled component modelling for inter- and transdisciplinary climate change impact research: Dimensions of integration and examples of interface design, Environmental Modeling and Software, 60, 180-187.

Yuksel G., 2014, Sea surface temperature anomalies at the Mediterranean Coast of Turkey (Period: 1968-2010), Procedia - Social and Behavioral Sciences, 31, 476-486. 